\title{
Skeletal Dysplasias Associated with Mild Myopathy-A Clinical and Molecular Review
}

\author{
Katarzyna A. Piróg and Michael D. Briggs \\ Wellcome Trust Centre for Cell Matrix Research, Faculty of Life Sciences, University of Manchester, Michael Smith Building, \\ Oxford Road, Manchester M13 9PT, UK \\ Correspondence should be addressed to Katarzyna A. Piróg, katarzyna.pirog@manchester.ac.uk
}

Received 9 February 2010; Accepted 15 March 2010

Academic Editor: Henk L. M. Granzier

Copyright $(2010$ K. A. Piróg and M. D. Briggs. This is an open access article distributed under the Creative Commons Attribution License, which permits unrestricted use, distribution, and reproduction in any medium, provided the original work is properly cited.

\begin{abstract}
Musculoskeletal system is a complex assembly of tissues which acts as scaffold for the body and enables locomotion. It is often overlooked that different components of this system may biomechanically interact and affect each other. Skeletal dysplasias are diseases predominantly affecting the development of the osseous skeleton. However, in some cases skeletal dysplasia patients are referred to neuromuscular clinics prior to the correct skeletal diagnosis. The muscular complications seen in these cases are usually mild and may stem directly from the muscle defect and/or from the altered interactions between the individual components of the musculoskeletal system. A correct early diagnosis may enable better management of the patients and a better quality of life. This paper attempts to summarise the different components of the musculoskeletal system which are affected in skeletal dysplasias and lists several interesting examples of such diseases in order to enable better understanding of the complexity of human musculoskeletal system.
\end{abstract}

\section{Introduction}

Skeletal dysplasias are a diverse group of diseases primarily affecting the development of the osseous skeleton. They manifest with disproportionate short stature, malformations, and/or deformations and range from relatively mild to severe and lethal conditions. To date there are over 250 unique and well-characterised skeletal dysplasias, many of which can be grouped into different diagnostic groups and/or bone dysplasia families based on clinical similarities [1]. It is important to note that skeletal dysplasia mutations may also influence other nonskeletal organs, often mechanically by tightening the tracts in the body due to skeletal defects. For example, children with skeletal dysplasias often have respiratory problems and mental problems sometimes occur due to craniofacial defects [2]. Early diagnosis of skeletal dysplasias is therefore crucial for patient management and may enable relatively normal growing up and life span.

Skeletal dysplasias may sometimes be associated with muscular disorders. Skeletal muscle, tendon and ligament, and the bones themselves form a complicated biomechanical system of levers and forces; therefore, abnormalities in one tissue may potentially affect the others. It is known that bones react and remodel according to the forces exerted by muscles. Tendons and ligaments also repair and remodel according to the biomechanical forces exerted upon them. Therefore, for the wellbeing of the patient, it is important to recognise all the tissues that the disease may be affecting. In this paper we summarise the relationships between different tissues in the musculoskeletal system and discuss several skeletal dysplasias in which muscle and/or tendon weakness has been recognised and described. This detailed paper will provide better understanding of the musculoskeletal biology and may enable better diagnosis and management of the patients in future.

\section{Biomechanics of the Musculoskeletal System}

2.1. Bones and Growth Plate Cartilage. Bone is a hard connective tissue consisting of osteocytes embedded in an abundant extracellular matrix (ECM). Bones act as a scaffold, attachment points, leverage, and protection for soft tissues. 


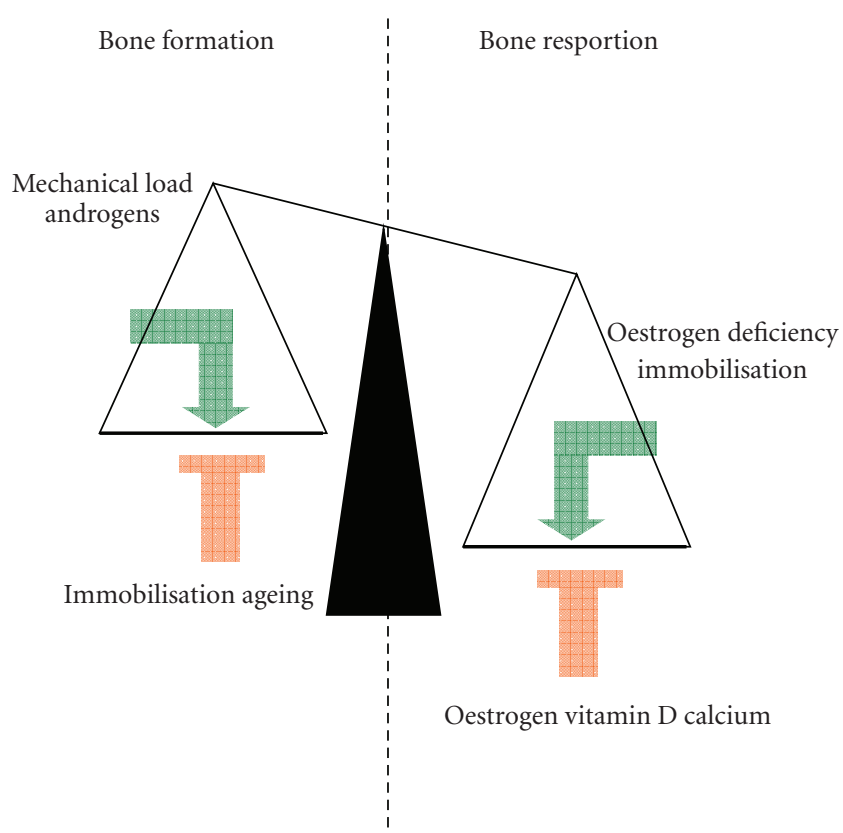

(a)

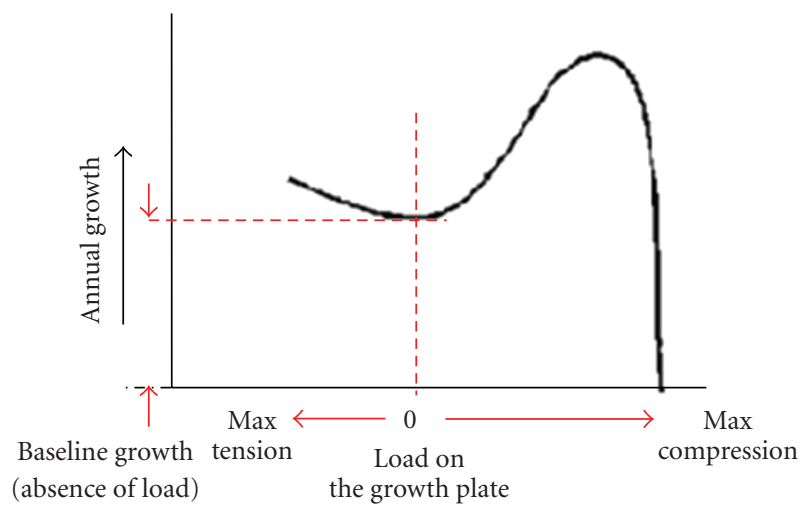

(b)

Figure 1: (a) A schematic representation of processes that may influence bone formation and resorption [3]. (b) A graph illustrating the Hueter-Volkman law [4].

During life, and to enable growth, repair and mineralisation, the bone is constantly being remodelled by osteoblasts and osteoclasts [5]. Furthermore, bone is a dynamic tissue which is able to remodel in response to the mechanical load. For example, an increase in loading bone formation increases and resorption decreases whilst unloading of the bone has an opposite effect (Figure 1(a)) [3].

The human skeleton consists of 206 bones of differing shapes and functions and distributed throughout the entire body [6]. Surprisingly, however, this complicated scaffolding is formed by only two distinct and very conserved processes [7]. Both processes begin with mesenchymal condensation. Bones of the craniofacial skeleton evolve from migrating neural crest cells in a process called intramembranous ossification. The rest of the skeleton is formed by mesenchymal cells forming a cartilage anlagen, which is later replaced by

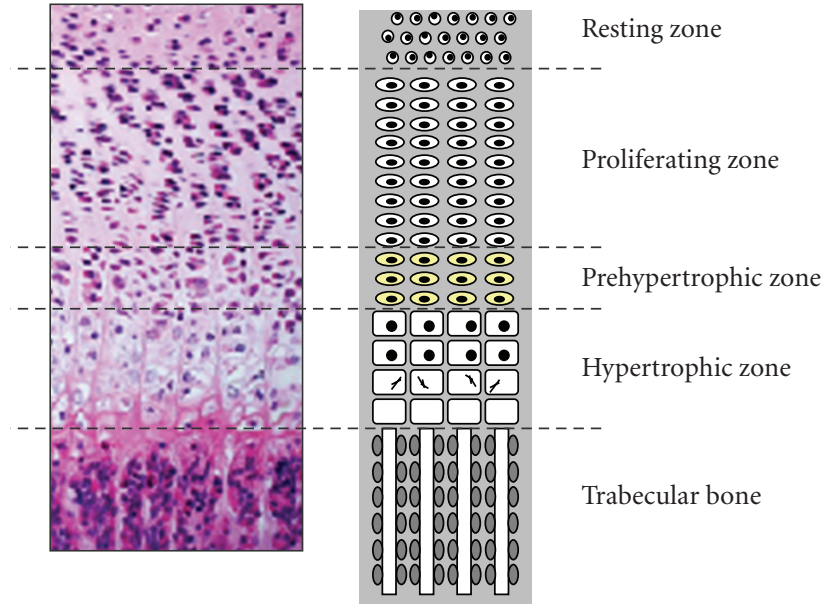

Figure 2: A histological H\&E (haematoxylin and eosin) stained image of an adult mouse growth plate and a schematic representation of differentiation zones in the tissue. In the growth plate several distinct structural zones can be identified, reflecting the gradual transition of cells through different stages of differentiation [13]. Resting zone acts as a reserve of precursor cells for the proliferating chondrocytes in the columns [10]. Proliferating zone is where the cells flatten and divide, laying down a cartilage extracellular matrix that will later serve as a scaffold for bone formation [14]. In the prehypertrophic zone, the cells enter the maturation zone and begin to enlarge. In the hypertrophic zone, the chondrocytes and their lacunae become 5-12 times bigger [14]. These cells eventually die, triggering vascularisation and bone formation.

bone in endochondral (i.e., "in cartilage") ossification [8]. Both ossification pathways are also implicated in bone repair at later stages of life, with intramembranous ossification being the method of repair for stabilised fractures, whilst unstable fractures heal via endochondral ossification [9]. These separate pathways share many common regulatory genes and proteins, local paracrine regulators, blood stream hormones, and transcription factors [10]. Mechanical forces are also extremely important for proper development of the skeleton, influencing the shape of the bones, their repair processes, and signalling pathways $[11,12]$.

Limb development begins with the condensation of mesenchyme after which the cells differentiate into chondrocytes, which form the cartilaginous template [7]. As the cartilage grows, the cells are forced apart by the extracellular matrix and become encapsulated in the thickening matrix. Meanwhile, within the cartilage anlagen, the encapsulated cells die due to their intensive growth and calcium salt deposition, and the ECM eventually erodes [15]. The blood vessels invade the cartilage, bringing bone-forming cells, which differentiate into osteoblasts and secrete additional extracellular matrix. This matrix is subsequently calcified forming trabeculae, some of which are later reabsorbed by the osteoclasts thus forming a bone marrow cavity [16]. As the bones continue to grow, a secondary ossification centre is established in the epiphyses [10] and between the shaft of the bone and the epiphysis a cartilage growth plate is formed (Figure 2), allowing longitudinal bone growth. The 
thickening of bone is achieved by depositing further layers on the periosteum side by osteoblasts, and widening of the bone marrow cavity by osteoclasts. Eventually, the epiphysis and metaphysis in the bone fuse, usually around puberty, forming a diaphyseal mature bone [11].

Growth plate cartilage extracellular matrix is composed of type II collagen fibers and is abundant in proteoglycans, specifically aggrecan. This makes it a relatively compliant tissue and so it is able to respond to mechanical and gravity forces. To a certain extent, growing bones are able to align themselves according to the gravity forces exerted upon them, as can be seen in the correction of a mild genu varum in toddlers [17]. However, strong compression inhibits bone growth and tension has an opposite effect by increasing growth in bone length $[4,18]$. This is known as the Hueter-Volkman law (Figure 1(b)), which was further defined by Frost in the twentieth century and is often used by clinicians in surgical correction of certain limb deformities $[4,17]$. Lack of mechanical loading also results in decreased bone formation, as shown by weightlessness and suspension experiments (Figure 1(a)) [19-21].

Gravity induced mechanosensing in the growth plate cartilage is achieved by a microtubule-based organelle called the primary cilium [22-24]. Primary cilia are cytoplasmatic protrusions that are associated with many proteins implicated in signal transduction, specifically integrins and extracellular matrix receptors, and enable the cells to respond to mechanical stimuli [22]. They exist on almost every cell in the human body and are very important for mechanosensing and biomechanics of many different tissues.

2.2. Articular Cartilage. Cartilage is a highly specialised connective tissue. Its mechanical properties allow it to withstand compressive forces and also to a smaller extent resist shearing and torsional forces [5]. Cartilage consists mostly of an extracellular matrix and its structure varies according to species, location, and age of the tissue [5]. Hyaline cartilage is the most abundant type of cartilage. It is a precursor to the growth plate (physis), and it is also found at the articular surface of bones, where it acts as a shock absorber and protection for the underlying subchondral bone [25]. Chondrocytes in the hyaline cartilage are ovoid, ranging in shape from round to flat [5]. Each chondrocyte occupies a space (lat. lacuna) encapsulated by the extracellular matrix, which is important for cartilage biomechanical properties. Chondrocyte together with its pericellular matrix is often termed "chondron" [26]. It has been shown that pericellular matrix of articular cartilage has a precise macromolecular architecture, with a high content of proteoglycans, such as aggrecan, embedded in the collagen matrix [27]. Aggrecan retains water, thus contributing to the cartilage tissue elasticity [28]. The shape of individual chondrons is also important and they respond to the gravitational forces by producing a compact matrix "cap" pointing towards the surface of the tissue and a looser "tail" extending into the ECM below [27]. Chondrons have often been referred to as fluid bladders and indeed they seem to function in a similar manner [29]. When cartilage is subjected to compression, the liquid is pushed out of the proteoglycan complex and the collagen rich matrix deforms, thus increasing the pressure within the chondron. This change in osmotic pressure due to escaping water protects the chondrocyte and enables its full recovery at unloading [29]. Chondrocytes also have a primary cilium which helps them sense these changes in forces $[22,23,26]$. This seems to be especially important in the aetiology and management of osteoarthritis where even a ligamentous instability or a weakness of periarticular muscles, and therefore an abnormal biomechanical environment, may result in joint degeneration $[30,31]$.

\subsection{Entheses (at the Bone to Tendon Junction). Fibrocartilage} is an intermediate tissue between the hyaline cartilage and dense fibrous tissues $[5,32]$. It only has a few chondrocytes in the lacunae, and its matrix contains many thick collagen fibres arranged in an ordered fashion. It can be found in invertebral discs, symphysis pubis, articular disc of the sternoclavicular and temperomandibular joints, the menisci of the knee joints, and places where ligaments or tendons attach to bones and is formed as tendon's reaction to compressive load [33]. Fibrocartilage is associated with epiphyseal tendons and ligaments and is important in force transduction as it dissipates the stress on the tendon fibers near the bone $[32,34,35]$. Its molecular composition is similar to that of tendon, but several cartilage specific molecules, such as type II and type IX collagen and aggrecan, are also present in the matrix [33].

2.4. Tendon and Ligament. Tendon (Figures 3(a) and 3(b)) and ligament are soft collagenous tissues, linking muscle to bone and bone to bone, respectively. They consists of densely packed bundles of fibrous collagen and are characterised by high tensile strength and elasticity [5]. Tendon and ligament both have similar hierarchical structure, consisting of fascicles, which are built of smaller basic fibrils and fibroblasts [36]. The main component of the basic fibril is type I collagen. Both ligaments and tendons are surrounded by a sheath of transparent material called the synovial membrane, a delicate connective tissue layer secreting synovium, a viscous lubricating fluid [5].

Tendons act as buffers and storage of elastic kinetic energy during walking [37]. They can remodel according to the forces exerted upon them $[34,38]$. It has been shown that the immobilisation of limbs leads to a decrease in collagen turnover in the tendon and a decrease in tendon diameters [39], and conversely, exercise leads to an increase in tendon diameter and collagen turnover [40]. Increase in tendon diameters correlates with an increase in the stiffness of the tissue [38], which means thicker tendons can withstand higher tensile forces exerted upon them by stronger muscles. Tendons also become thicker and less compliant with age [37], which together with age-associated muscle wasting helps explain the weakness and difficulties in walking experienced by the elderly [41].

2.5. Myotendinous Junction and Perimysium. Another structure that is biomechanically important for conveying forces from muscle to tendon is the myotendinous junction (MTJ; Figure 4). This is the site where tendon meets, and merges, 


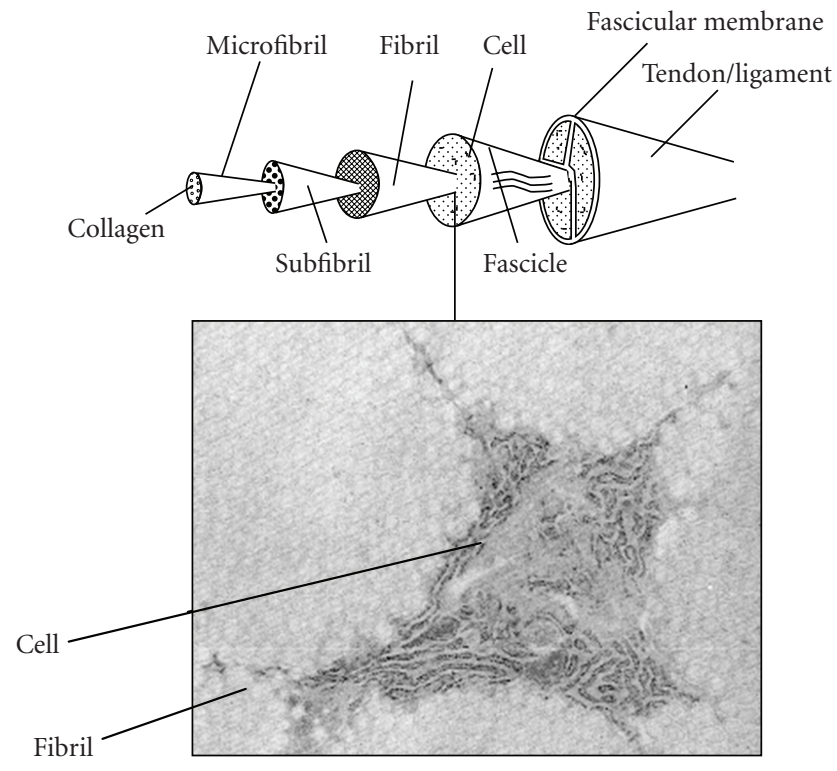

(a)

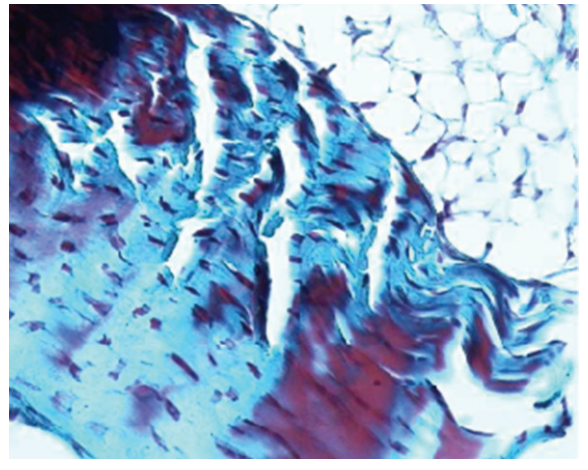

(b)

FIGURE 3: (a) A schematic representation of tendon hierarchical structure and a transmission electron microscopy image of a tenocyte embedded in the collagen matrix. (b) A histological (Gomori trichrome, staining collagenous tissues blue) image of a longitudinal section of patellar tendon showing parallel running collagen bundles in the tissue.

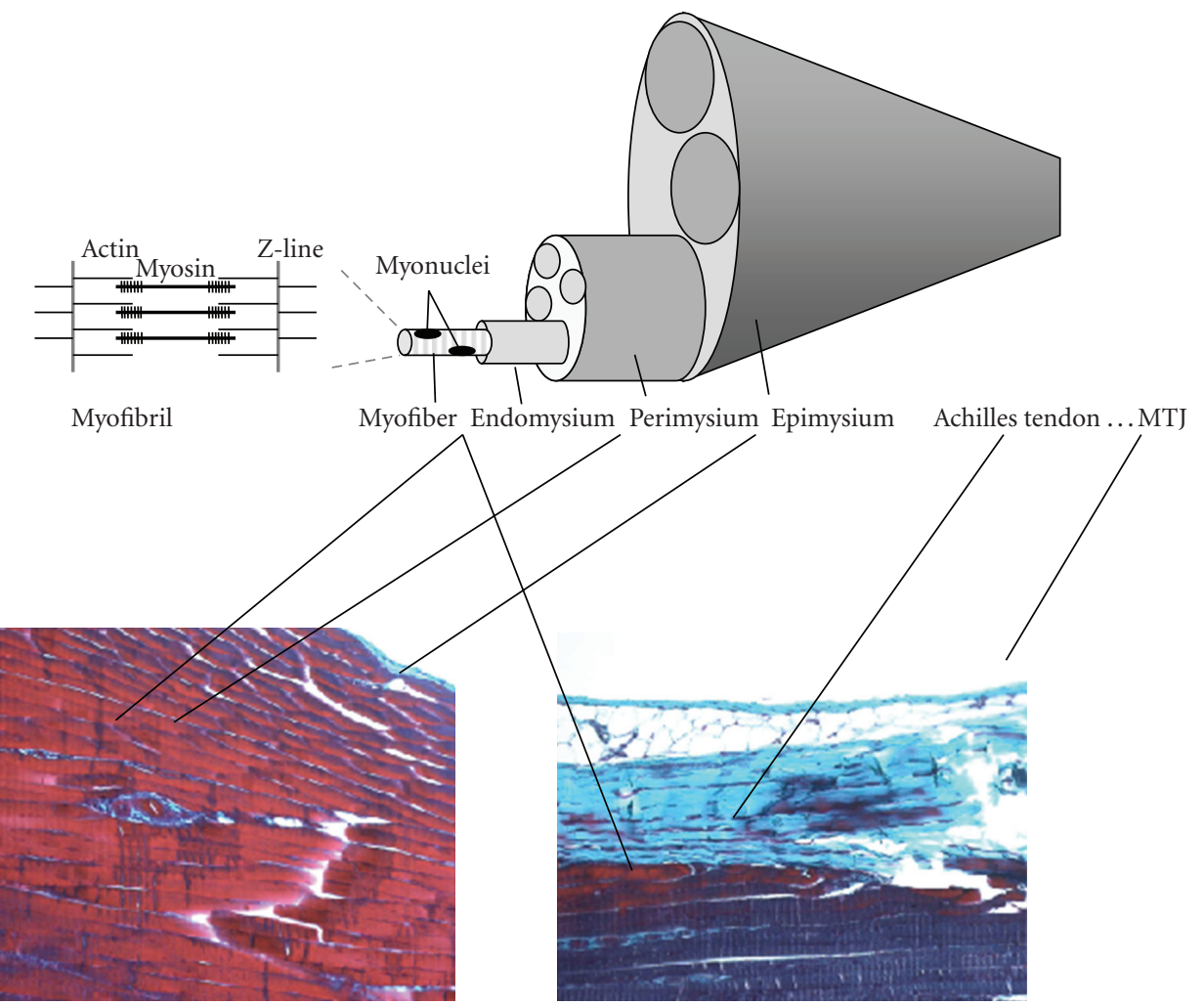

FIGURE 4: Schematic representation of the skeletal muscle structure and histological images of a longitudinal section of murine skeletal muscle and of murine Achilles tendon myotendinous junction (MTJ) stained with a trichrome Gomori stain to visualise collagenous tissues (staining muscle red, collagenous tissues blue, and nuclei black). 
with the skeletal muscle and the point where muscle contractile forces are transmitted to the tendon [42]. The myotendinous junction membrane is extensively folded. This means that the tensile stress exerted by the contracting muscle fibers becomes shear stress instead, thus increasing the strength of the junction and protecting the tissues from injury [42]. The myotendinous junction is also connected to the collagenous perimysium surrounding the skeletal muscle fascicles [43]. The perimysium forms a lattice structure within the skeletal muscle and is involved in transmission of lateral forces in the muscle. MTJ and perimysium are together responsible for conveying the forces from muscle to tendon $[43,44]$.

2.6. Skeletal Muscle. Skeletal muscle acts as the motor of the body and is essential for locomotion. As such it has a very complex hierarchical structure (Figure 4). Each myofiber is a one multinuclear cell (with nuclei located to the periphery) that often spans the length of the entire muscle. Most of the myofiber is filled with contractile myofibrils consisting of actin and myosin and responsible for muscle contraction. The discovery of costameres by Pardo et al. in 1983 showed the first direct link between the surrounding extracellular matrix and the myofibers [45]. Costameres are regularly spaced around the Z-lines of the skeletal muscle and play a role in lateral force transmission, as shown by single myofiber studies performed by Street et al. [44, 46]. Every myofiber is covered by a connective tissue sheath called the endomysium [47]. Groups of muscle fibers are covered by another connective tissue sheath called the perimysium, which transmits the lateral forces between the muscle bundles [48]. Not every myofiber spans the entire muscle length and connects to the myotendinous junction; however, all the fibrous extracellular matrices are interconnected and eventually lead to the myotendinous junction and to the tendon itself [44]. Muscle can also remodel and adapt to the mechanical load [49], and muscle hypertrophy is often seen as a result of exercise [50].

\section{Skeletal Dysplasias: Genetics Disorders Affecting the Osseous Skeleton}

Skeletal dysplasias are a group of skeletal and musculoskeletal diseases that affect the development of the osseous skeleton. There are over 250 well-characterised phenotypes known to date, which affect the development of both flat and long bones [51]. The many different genes that are mutated in skeletal dysplasias span a wide range of cellular and metabolic processes and include those involved in the extracellular matrix, metabolic pathways, folding and degradation of macromolecules, hormones and signal transduction mechanisms, nuclear proteins and transcription factors, oncogenes and tumour suppressor genes and RNA, and DNA processing and metabolism [52].

Many skeletal dysplasia phenotypes are characterised by severe deformations and/or malformations of numerous skeletal elements and with such conditions it is sometimes easy to overlook other clinical aspects, such as the effect these skeletal abnormalities may have on the soft tissues of the body [2]. Skeletal dysplasias may result in tightening of the tracts in the body thus affecting breathing and patient's wellbeing. Shorter limbs may result in a different distribution of biomechanical forces exerted by the muscles and thus may contribute to difficulties in walking. Furthermore, many of the extracellular matrix genes expressed in bone and cartilage and involved in skeletal dysplasias are also present in other musculoskeletal tissues, such as muscle and tendon, and may affect patients' well-being and quality of life.

\section{Skeletal Dysplasias That Are Associated with Myopathies}

There are several skeletal dysplasia phenotypes in which myopathy is a recognised neuromuscular complication of the disease. In some of the cases, the muscle pathology stems directly from the fact that the mutant protein is expressed in the muscle as well as in cartilage and bone, but in others the effect appears to be more indirect. A detailed analysis of the muscular symptoms in these phenotypes is very important since the neuromuscular complications often manifest prior to the skeletal deformations, which may arise during prepubertal growth, and therefore might allow quicker diagnosis and better management of the patient. We present a short summary of these conditions below and also in Table 1.

\subsection{Multiple Epiphyseal Dysplasia: An Indirect ECM Defect?} Multiple epiphyseal dysplasia (MED) is a skeletal dysplasia in which an associated myopathy has only recently been recognised and reported in patients [53-55]. MED belongs to a "bone dysplasia family" that also includes the related and more severe disease known as pseudoachondroplasia (PSACH) [51, 56]. Together these phenotypes form a distinct spectrum of disease severity ranging from a mild MED through to severe PSACH at the other end of the spectrum. The PSACH-MED phenotype is characterised by disproportionate short stature, lower limb deformations (genu varum and genu valgum), joint laxity, and early onset degenerative joint disease [57]. Radiographic features of PSACH manifest in the epiphyses and the metaphyses of the long bones and in MED are restricted to the epiphyses [58]. PSACH and the more severe forms of MED result from mutations in the gene encoding cartilage oligomeric matrix protein (COMP), a pentameric ECM bridging molecule found in cartilage, tendon, ligament, and skeletal muscle [59]. PSACH-MED mutations in COMP cluster in the exons encoding the calcium-binding thrombospondin type 3 repeats (T3) and the $\mathrm{C}$-terminal domain (CTD) of COMP. In chondrocytes the expression of these mutations results in various levels of endoplasmic reticulum (ER) stress and cell death $[59,60]$. A role for COMP in collagen fibrillogenesis has been proposed and it is thought to be one of the catalysts of this process [61]. Furthermore, in the cartilage extracellular matrix COMP plays a bridging role and is able to interact with other ECM molecules such as matrilin-3, type IX collagen, aggrecan, fibronectin, and integrins [6265]. It is therefore not surprising that other MED-causing 
TABLE 1: Summary of the published skeletal dysplasias associated with a mild myopathy phenotype.

\begin{tabular}{|c|c|c|c|c|c|}
\hline Disease name & $\begin{array}{l}\text { Multiple epiphyseal } \\
\text { dysplasia (MED) }\end{array}$ & $\begin{array}{l}\text { Multiple epiphyseal } \\
\text { dysplasia (MED) }\end{array}$ & $\begin{array}{l}\text { Camurati-Englemann } \\
\text { disease (CED) }\end{array}$ & $\begin{array}{l}\text { Marfan syndrome } \\
(\mathrm{MFS} 1)\end{array}$ & $\begin{array}{l}\text { Schwartz-Jampel } \\
\text { syndrome (SJS1) }\end{array}$ \\
\hline $\begin{array}{l}\text { Alternative } \\
\text { name }\end{array}$ & EDM3 & EDM1 & $\begin{array}{l}\text { Progressive diaphyseal } \\
\text { dysplasia }\end{array}$ & & $\begin{array}{l}\text { Chondrodystrophic } \\
\text { myotonia }\end{array}$ \\
\hline $\begin{array}{l}\text { Mode of } \\
\text { inheritance }\end{array}$ & Autosomal dominant & Autosomal dominant & Autosomal dominant & Autosomal dominant & Autosomal recessive \\
\hline Gene & COL9A3 & COMP & TGF- $\beta 1$ & Fibrilin-1 & Perlecan \\
\hline $\begin{array}{l}\text { Skeletal } \\
\text { symptoms }\end{array}$ & $\begin{array}{l}\text { Epiphyseal dysplasia, } \\
\text { early onset degenerative } \\
\text { joint disease (knees), } \\
\text { mild or no short limbed } \\
\text { dwarfism }\end{array}$ & $\begin{array}{l}\text { Epiphyseal dysplasia, } \\
\text { early onset } \\
\text { degenerative joint } \\
\text { disease, mild short } \\
\text { limbed dwarfism }\end{array}$ & $\begin{array}{l}\text { Thicker bone } \\
\text { diaphyses, thicker } \\
\text { bones of the skull, } \\
\text { tighter bone canals, } \\
\text { bone pain, } \\
\text { hyperlordosis, } \\
\text { scoliosis }\end{array}$ & $\begin{array}{l}\text { Increased height, } \\
\text { scoliosis, thoracic } \\
\text { lordosis, highly } \\
\text { arched palate with } \\
\text { tooth crowding }\end{array}$ & $\begin{array}{l}\text { Short femurs, short } \\
\text { stature, micrognathia, } \\
\text { kyphoscoliosis, joint } \\
\text { deformities, coxa } \\
\text { valga, irregular capital } \\
\text { femoral epiphyses }\end{array}$ \\
\hline Skeletal onset & Childhood & $\sim 3$ years & $\sim 3$ years & Childhood & $\begin{array}{l}<3 \text { years, muscle } \\
\text { stiffness after birth }\end{array}$ \\
\hline $\begin{array}{l}\text { Muscular } \\
\text { symptoms }\end{array}$ & $\begin{array}{l}\text { Mild muscle weakness, } \\
\text { difficulty rising form the } \\
\text { floor }\end{array}$ & $\begin{array}{l}\text { Muscle weakness, easy } \\
\text { fatigue, difficulty } \\
\text { rising form the floor }\end{array}$ & $\begin{array}{l}\text { Easy fatigue, proximal } \\
\text { muscle weakness and } \\
\text { atrophy, waddling gait }\end{array}$ & $\begin{array}{l}\text { Mild to moderate } \\
\text { joint laxity, muscle } \\
\text { weakness, muscle } \\
\text { atrophy, hypoplasia, } \\
\text { cannot increase } \\
\text { muscle mass in } \\
\text { response to exercise }\end{array}$ & $\begin{array}{l}\text { Mild largely } \\
\text { non-progressive } \\
\text { muscle weakness, } \\
\text { stiffness, myotonic } \\
\text { myopathy, waddling } \\
\text { gait, crouched stance, } \\
\text { hypertrophy, reduced } \\
\text { tendon reflexes, joint } \\
\text { contractures }\end{array}$ \\
\hline CK levels & Mildly elevated & $\begin{array}{l}\text { Normal or mildly } \\
\text { elevated }\end{array}$ & Elevated up to $40 \%$ & $\begin{array}{l}\text { Normal or mildly } \\
\text { elevated }\end{array}$ & $\begin{array}{l}\text { Normal or mildly } \\
\text { elevated }\end{array}$ \\
\hline $\begin{array}{l}\text { Muscle } \\
\text { biopsy }\end{array}$ & $\begin{array}{l}\text { Mild myopathy, a slight } \\
\text { variability in fiber size }\end{array}$ & $\begin{array}{l}\text { No variability in fiber } \\
\text { size, scattered } \\
\text { basophilic fibers } \\
\text { and/or small atrophic } \\
\text { fibers }\end{array}$ & $\begin{array}{l}\text { Often normal, } \\
\text { occasional variability } \\
\text { in fiber size }\end{array}$ & $\begin{array}{l}\text { Sometimes myopathic } \\
\text { changes seen, } \\
\text { abnormalities in } \\
\text { fibrilin-1 } \\
\text { immunoreactivity }\end{array}$ & $\begin{array}{l}\text { Central nuclei, varied } \\
\text { fiber size, changes of } \\
\text { fiber type }\end{array}$ \\
\hline $\begin{array}{l}\text { Muscle } \\
\text { electron } \\
\text { microscopy }\end{array}$ & - & - & $\begin{array}{l}\text { Thicker basement } \\
\text { membrane around } \\
\text { the blood vessels, few } \\
\text { fibers with } \\
\text { accumulated } \\
\text { mitochondria }\end{array}$ & - & - \\
\hline EMG & - & - & $\begin{array}{l}\text { Short small action } \\
\text { potentials in some } \\
\text { muscles, myopathic }\end{array}$ & $\begin{array}{l}\text { Myopathic and } \\
\text { neurogenic }\end{array}$ & $\begin{array}{l}\text { Myotonic } \\
\text { abnormalities }\end{array}$ \\
\hline $\begin{array}{l}\text { Other } \\
\text { affected } \\
\text { tissues }\end{array}$ & - & - & $\begin{array}{l}\text { Liver, spleen, gonads } \\
\text { (hepatosplenomegaly } \\
\text { and hypogonadism) }\end{array}$ & $\begin{array}{l}\text { Eyes: myopia, ectopia } \\
\text { lensis, corneal flatness }\end{array}$ & $\begin{array}{l}\text { Eyes: myopia, } \\
\text { blepharophimosis }\end{array}$ \\
\hline $\begin{array}{l}\text { Possible } \\
\text { therapy }\end{array}$ & Not available & Not available & Corticosteroids & $\begin{array}{l}\text { Lasartan (aortic } \\
\text { aneurism, and muscle } \\
\text { involvement) }\end{array}$ & $\begin{array}{l}\text { Reducing muscle } \\
\text { stiffness, } \\
\text { anticonvulsants and } \\
\text { antiarrhythemics }\end{array}$ \\
\hline
\end{tabular}

mutations were found in genes encoding proteins known to interact with COMP such as matrilin-3 and type IX collagen, although the precise rationale for this genetic heterogeneity of MED has yet to be determined.

Until recently, PSACH-MED has primarily been described as a disease affecting bone growth, joint stability, and ligamentous laxity. In 2000 however, a form of MED resulting from a mutation in one of the type IX collagen genes (COL9A3) was as associated with a mild myopathy [54]. This initial observation was followed by the recognition that some forms of PSACH-MED resulting from CTD-COMP mutations may also present with mild myopathy $[53,55]$ (Tables 1 and 2).

4.1.1. MED Resulting from Mutations in COL9A3 (EDM3). In an MED family with a COL9A3 mutation patients 
presented with proximal muscle weakness (despite predominantly distal skeletal changes) and mildly elevated levels of creatine kinase (CK; an indicator of muscle degeneration and myopathy). These individuals tired easily and a muscle biopsy from one affected family member showed mild myopathic changes characterised by a mild variability in fiber size [54]. Interestingly, there is no evidence that type IX collagen is expressed in skeletal muscle as a fully functioning trimer $[66,67]$. Therefore, it is tempting to speculate that the pathology in this case arises from an abnormal enthesis (the tendon to bone attachment site where type IX collagen is expressed). This may also explain why no gross myopathic changes were seen in the muscle biopsy from the patient, which would be the case if a muscle specific structural protein was mutated. Our recent analysis of a CTD-COMP mutant mouse model provided evidence in support of this hypothesis.

\subsubsection{PSACH-MED Resulting from Mutations in COMP} (EDM1). MED-COMP patients with a CTD-COMP mutation and an associated myopathy were described in 2003 by Jakkula et al. [53]. They suffered from muscle weakness from 3 years of age and had mildly elevated CK levels; however a muscle biopsy was not performed at the time. In 2005, a further two CTD-COMP mutations were reported by Kennedy et al. [55] (Table 2). The onset of the disease was early and included muscle weakness, fatigue, and difficulty rising from the floor, in comparison to the patient reported by Jakkula; the CK levels were also with normal limits. A biopsy of the patients' muscle showed no variability in fiber size, however, scattered basophilic and small atrophic fibers were noted, indicating a mild myopathy [55]. Inconclusive data exists with respect to the expression of COMP in skeletal muscle and tendon $[69,70]$; therefore we analysed a knock-in mouse model carrying a CTD-COMP mutation to determine the pathomolecular mechanisms of PSACH-MED related myopathy.

4.1.3. Myopathy in Knock-In Transgenic Mouse Model of $P S A C H / M E D$. We have recently reported the clinical phenotype and investigated the pathology of PSACH-MED associated myopathy using a transgenic mouse model with a T585M COMP mutation in the C-terminal domain of COMP [71]. We detected COMP protein in skeletal muscle and in the tendons and ligaments of wild type and mutant mice, confirming that it is expressed in all of these tissues. Mice carrying the T585M CTD-COMP mutation experienced a progressive muscle weakness even though histological evidence of myopathy was found only at the myotendinous and perimysial junctions. The collagen fibril organisation was abnormal in mutant tendons and characterised by an overall increase in fiber diameter with a corresponding increase in the number of branching or bifurcating fibrils. These changes had the effect of producing thinner and more lax tendons.

COMP was expressed throughout skeletal muscle and tendon, yet the mutation resulted in a localised myopathy and a generalised tendinopathy. Therefore, we concluded

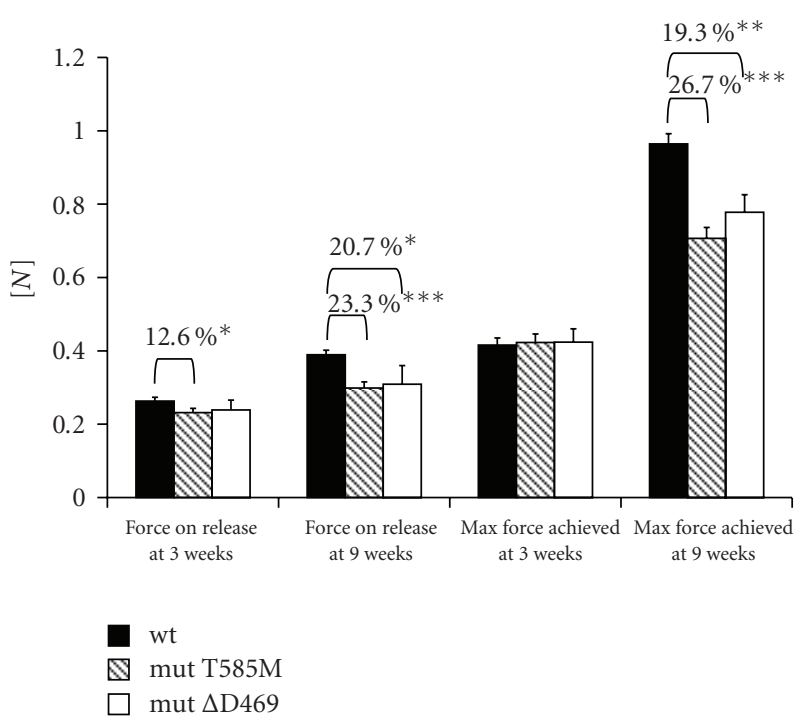

Figure 5: Grip strength measurement in COMP-CTD T585M knock-in mice and COMP-T3 $\triangle \mathrm{D} 469$ knock-in mice at 3 weeks of age. COMP-CTD mice were getting tired and let go of the apparatus easier than their wild type controls, although they were not generally weaker at 3 weeks of age, as seen by the maximum strengths registered $(n=15)$ [71]. COMP $\triangle \mathrm{D} 469$ mice were not getting tired and had the same maximum strength as the wild type controls at 3 weeks of age; however, by 9 weeks they were significantly weaker than their wild type littermates and tired easier, which is indicative of a mild myopathy $(n=5)$. Key: wt: wild type, mut: homozygous for the mutation, ${ }^{*} P<.05$, ${ }^{*} P<.01$, ${ }^{* * *} P<.001$ (independent samples $t$-test).

that the given myotendinous and perimysial junctions are responsible for transmitting the forces between the tendon and muscle fibers; the myopathy was perhaps the result of an underlying tendon problem. This finding is very important as it may help explain the myopathy seen in MED patients with type IX collagen gene mutations, and more recently, with matrilin-3 mutations (Table 2). Both of these molecules are not expressed in skeletal muscle; however, they are present in the fibrocartilage attachment point (enthesis) between the tendon and bone. A disruption to mechanical forces transmitted to the muscle and an altered ability of those tissues to remodel following stress may explain some of the musculoskeletal complications of the MED phenotype.

To test the hypothesis that myopathy is specifically associated with CTD-COMP mutations localised near the potential collagen and integrin binding sites, we have investigated a second mouse model, COMP $\triangle \mathrm{D} 469$ knockin mice (T3-COMP mutation), for muscle weakness using the experimental set-up as previously described in [71]. At 3 weeks of age we found no evidence of muscle weakness in $\Delta$ D469 mutant mice (Figure 5); however, by 9 weeks of age the mutant mice were weaker than their wild type littermates and tired easier, similar to the COMP-CTD mutant mice. This indicates that PSACH-MED COMP related myopathy may be a mutation specific phenomenon and be related directly to the proximity of the mutation to the potential 
TAble 2: Patient and mutation data were obtained from the European Skeletal Dysplasia Network (ESDN reference numbers) or recent publications, as referenced.

\begin{tabular}{|c|c|c|c|c|c|}
\hline Reference & Features & Diagnosis & Gene & Mutation & Effect \\
\hline ESDN 01071 & $\begin{array}{l}\text { - Fatigue during walking } \\
\text { - Muscle disease suspected by paediatrician }\end{array}$ & MED & MATN3 & D176V & Potential misfolding \\
\hline ESDN 01013 & $\begin{array}{l}\text { - Mild proximal muscle weakness at } 7 \text { years } \\
\text { - Difficulty rising from squatting position }\end{array}$ & MED & COL9A2 & $\mathrm{c} 186 \mathrm{G}>\mathrm{C}$ & Exon skipping \\
\hline ESDN 01003 & - Mild muscle weakness & MED & COL9A2 & $\mathrm{c} 186+4 \mathrm{a}>\mathrm{c}$ & Exon skipping \\
\hline$[68]$ & $\begin{array}{l}\text { - Muscle weakness } \\
\text { - Suspected (unproven) muscular dystrophy } \\
\text { - Problems with standing up from sitting position } \\
\text { - Problems walking on stairs } \\
\text { - Biopsy: } \\
\text { - No morphological or histochemical changes } \\
\text { - No fibers with central nuclei } \\
\text { - Variation in fiber size } \\
\text { - No degradation, regeneration, or necrosis } \\
\text { - ATP + CrP production from pyruvate } \\
\text { decreased }\end{array}$ & MED & COL9A2 & $\mathrm{c} 186+2 \mathrm{t}>\mathrm{c}$ & Exon skipping \\
\hline$[68]$ & $\begin{array}{l}\text { - Neurological evaluation for abnormal walking } \\
\text { pattern at } 6 \text { years } \\
\text { - Proximal muscle weakness lower extremities } \\
\text { - Family also affected (father, sister, sister's } \\
\text { daughter) }\end{array}$ & MED & COL9A2 & $\mathrm{c} 186 \mathrm{G}>\mathrm{A}$ & Exon skipping \\
\hline$[54]$ & $\begin{array}{l}\text { - Proximal muscle weakness (reported to the } \\
\text { neuromuscular clinic at } 10 \text { years) } \\
\text { - Mildly elevated serum creatine kinase (CK) } \\
\text { levels } \\
\text { - Difficulty walking and climbing stairs from } 3 \\
\text { years on } \\
\text { - Difficulty rising from the floor } \\
\text { - Some signs of proximal muscle weakness in } \\
\text { family members } \\
\text { - Muscle biopsy: mild variability in fibre size }\end{array}$ & MED & COL9A3 & IVS2-1, G > A & Exon skipping \\
\hline ESDN 00385 & $\begin{array}{l}\text { - Some signs of mild myopathy } \\
\text { - Gower's sign (proximal muscle weakness) } \\
\text { - Waddling gait } \\
\text { - Difficulties climbing stairs } \\
\text { - CPK normal }\end{array}$ & PSACH & COMP & D326Y & $\begin{array}{l}\text { Potential retention } \\
\text { (T3 domain } \\
\text { mutation) }\end{array}$ \\
\hline
\end{tabular}


TABle 2: Continued.

\begin{tabular}{|c|c|c|c|c|c|}
\hline Reference & Features & Diagnosis & Gene & Mutation & Effect \\
\hline \multirow{8}{*}{ ESDN 00430} & - Reported to neurologist at age 2 & & & & \multirow{8}{*}{$\begin{array}{l}\text { Potential retention } \\
\text { (T3 domain } \\
\text { mutation) }\end{array}$} \\
\hline & - Diminished muscle strength in: & & & & \\
\hline & - Hips & & & & \\
\hline & - Shoulders & MED & COMP & E457del & \\
\hline & - Quadriceps muscle & & & & \\
\hline & - Feet-lifting muscles & & & & \\
\hline & - Diagnosed with a myopathy at 5 years & & & & \\
\hline & - Biopsy inconclusive & & & & \\
\hline \multirow{11}{*}[55]{} & - Difficulty walking at 2.5 years & \multirow{11}{*}{ MED } & \multirow{11}{*}{ COMP } & \multirow{11}{*}{ D605N } & \multirow{11}{*}{$\begin{array}{l}\text { Potential misfolding } \\
\text { (CTD mutation) }\end{array}$} \\
\hline & - Muscle weakness & & & & \\
\hline & - Tired easily & & & & \\
\hline & - Difficulty getting up from sitting & & & & \\
\hline & - CK levels normal & & & & \\
\hline & - EMG and nerve conduction velocities normal & & & & \\
\hline & - Biopsy: & & & & \\
\hline & - Mild myopathy, & & & & \\
\hline & - No variability in fibre size & & & & \\
\hline & - Scattered basophilic fibers & & & & \\
\hline & - Some small atrophic fibers & & & & \\
\hline \multirow{3}{*}[53,55]{} & - Muscle weakness from 3 years on & \multirow{3}{*}{ MED } & \multirow{3}{*}{ COMP } & \multirow{3}{*}{ R718W } & \multirow{3}{*}{$\begin{array}{l}\text { Potential misfolding } \\
\text { (CTD mutation) }\end{array}$} \\
\hline & - Referred to neuromuscular clinic at 5 years & & & & \\
\hline & - Mildly elevated CK levels & & & & \\
\hline
\end{tabular}

binding sites on COMP rather than the specific domain of the molecule.

4.1.4. PSACH and MED: New Findings. Recently, several PSACH and MED patients with COMP, type IX collagen, and also matrilin-3 mutations have been reported with muscular complications, and these patients were originally referred to neuromuscular clinics prior to the diagnosis of skeletal dysplasia. This seems to support our hypothesis that mutations in T3 domain of COMP and in other structural molecules of tendon and cartilaginous enthesis may also result in a mild myopathy. Blood samples from the patients showed normal or mildly increased CK levels and their muscle biopsy showed increased number of basophilic fibers, fiber necrosis, and/or variability in fiber diameters. We now present an updated summary of novel PSACH-MED mutations associated with myopathic changes (Table 2). Interestingly, some of the newly found COMP mutations associated with a myopathy cluster in the T3 repeats of the COMP protein. The T3 and CTD domains of COMP can form intramolecular interactions as demonstrated by the recent crystal structure model $[72,73]$. Therefore, the mutations that associate specifically with a myopathy may do so due to their specific locations, possibly near a potential collagen or integrin binding sites and/or the intramolecular binding sites within COMP, and myopathic phenotype may not segregate directly with the domain, but rather with a specific location of the mutation. Type IX collagen and matrilin-3 mutations' association with a myopathic phenotype may potentially be explained by the expression of these molecules in the fibrocartilaginous enthesis [33, 74]; however the pathomolecular mechanism of the muscle complications in these cases requires further investigation.

4.2. Schwartz-Jampel Syndrome: A Direct ECM Defect. An autosomal recessive disorder, Schwartz-Jampel syndrome (SJS1) [75], results form mutations in the extracellular matrix molecule perlecan [76]. Perlecan is a heparin sulphate 
proteoglycan that is a major component of basement membranes. It is expressed in cartilage, the endomysium of skeletal muscle, the nervous system, and in basement membranes throughout the body. It can interact with both fibroblast growth factor 2 (FGF2) and transforming growth factor beta $(\mathrm{TGF} \beta)$ and is believed to play a role in tissue growth [77]. Schwartz-Jampel syndrome is characterised skeletally by short stature, irregular epiphyses, bowed diaphyses, general joint deformities, and coxa valga. In skeletal muscle SJS1 manifests with myotonic myopathy and joint contractures [78]. The onset of the disease is quite early, from around 3 years of age, and the muscular phenotype often precedes the skeletal abnormalities. Another affected tissue is the eye with patients often suffering from myopia and a dysplasia of the eyelids [75]. Interestingly, the skeletal symptoms of SJS1 are at least in part due to a defect in sodium and potassium gradients in the muscle and these may be pharmacologically corrected [79]. What is extremely interesting is that perlecan is not a part of a voltage channel per se, rather it is expressed in the endomysial extracellular matrix, thus suggesting a link (perhaps mechanical) exists between voltage channels and signalling and the surrounding ECM.

4.3. Marfan Syndrome: An Indirect Signalling Defect. Marfan syndrome is an autosomal dominant musculoskeletal and ocular syndrome resulting from mutations in the extracellular matrix protein, fibrilin-1. Fibrilin-1 is a component of extracellular microfibrils that are present in many connective tissues such as lung, skin, kidney, blood vessels, cartilage, muscle, cornea, and tendon [80]. Marfan syndrome patients are characterised by abnormally high stature, scoliosis, and highly arched palate with a crowding of the teeth [81]. The muscular component (skeletal muscle) of Marfan syndrome has been largely ignored until relatively recently [82]. Muscular abnormalities can include muscle hypoplasia, hypotonia, and weakness, and some patients also have problems with increasing the muscle mass upon exercise. The hypoplasia and hypotonia possibly result from the increased availability of TGF $\beta 1$, which is known to bind to fibrilin associated latent TGF $\beta 1$ binding protein (LTBP). This may in turn affect the satellite cell differentiation and proliferation [83]. Furthermore, the patients' biopsy shows abnormal distribution of fibrilin-1 in the endomysium [82]. Recently losartan, an antagonist of TGF $\beta 1$, has been shown to alleviate aortic aneurysm in a mouse model of Marfan syndrome, and it may also help to reverse the muscular symptoms of Marfan syndrome [84]. Since the onset of muscular symptoms can precede the bone pathology and the muscular symptoms may soon be treatable, an early diagnosis based on muscular phenomena may lead to better management and better quality of life for these patients.

4.4. Camurati-Englemann Disease: A Direct Signalling Defect. Camurati-Engelmann disease (CED), also known as progressive diaphyseal dysplasia, is an early onset autosomal dominant skeletal dysplasia resulting in the thickening of the diaphyseal bones, sclerosis of the skull base, and bone pain [85]. The first symptoms usually manifest in early childhood and always before 30 years of age [86]. CED is caused by mutations in transforming growth factor $\beta 1$ (TGF $\beta 1$ ), a molecule very important in proliferation and differentiation of many different cell types, including those of cartilage and bone [87]. Interestingly, CED patients are often initially referred to neuromuscular clinics with a suspicion of muscular dystrophy. They present with an increasing muscle weakness, easy fatigue, and a characteristic waddling gait [88]. However, their plasma creatine kinase (CK) level (an indicator of muscle degeneration) is usually normal or only mildly elevated [89]. Muscle biopsies are often normal or show nonspecific changes, with some atrophic fibers (but no group atrophy) and thickened basement membrane around the small vessels. Some degree of perimysial fibrosis (but no endomysial fibrosis) is also observed in a proportion of patients [89]. Electromyographs (EMG) show small action potentials indicative of a myopathy in some muscles, especially around the pelvic girdle whereas other muscles are normal [89]. These observations are extremely important as muscular complications often manifest themselves prior to the severe skeletal symptoms and some of the radiographic features of CED may be prevented or are treatable with corticosteroids [90]. Therefore, a muscle biopsy/assessment at the right site combined with radiological evidence could potentially enable better and earlier diagnosis and treatment of these patients.

\section{Summary}

The mammalian musculoskeletal system is a complex system of different tissues and biomechanical properties. Together these tissues enable locomotion, protect soft organs from damage, and act as a scaffold for our bodies. We sometimes forget however that all these tissues often develop together, are in fact interconnected, and can interact with each other, and that affecting one may have an effect on the others. Understanding these intertissue relationships may also dramatically improve the therapies and management of certain diseases, such as the ones described in this paper. Early detection of an asymptomatic or a mild myopathy may lead to an earlier diagnosis of an underlying skeletal dysplasia [88]. Identification of the tissues affected by the disease, and a better understanding of the disease aetiology may also lead to the alleviation of some of the disease symptoms, better corrective surgery, and better management of the patients. Understanding the biomechanics of the interconnected musculoskeletal system may lead to better physiotherapies for osteoarthritis and many other bone/muscle related diseases. Therefore, a thorough and interdisciplinary investigation of musculoskeletal diseases and tissues is required to further our understanding of these systems and to enable better management and a better quality of life for patients in the future.

\section{Acknowledgments}

The work included from the authors' laboratories was funded by the Wellcome Trust (the second author is a Wellcome 
Trust Senior Research Fellow: Grant 084353/Z/07/Z), the EU (LSHM-CT-2007-037471), NIH (RO1 AR49547-01), and the ARC (grant 17221). Patient and mutation data were obtained from the European Skeletal Dysplasia Network (http://www.ESDN.org/). The research was undertaken in the Wellcome Trust Centre for Cell-Matrix Research and the Histology, Microscopy and Transgenic Core Facilities of the Faculty of Life Sciences at the University of Manchester.

\section{References}

[1] C. A. Francomano, I. McIntosh, and D. J. Wilkin, "Bone dysplasias in man: molecular insights," Current Opinion in Genetics and Development, vol. 6, no. 3, pp. 301-308, 1996.

[2] P. J. Mogayzel and C. L. Marcus, "Skeletal dysplasias and their effect on the respiratory system," Paediatric Respiratory Reviews, vol. 2, no. 4, pp. 365-371, 2001.

[3] S.-I. Harada and G. A. Rodan, "Control of osteoblast function and regulation of bone mass," Nature, vol. 423, no. 6937, pp. 349-355, 2003.

[4] H. M. Frost, "Biomechanical control of knee alignment: some insights from a new paradigm," Clinical Orthopaedics and Related Research, no. 335, pp. 335-342, 1997.

[5] P. M. Royce and B. Heinmann, Connective Tissue and Its Heritable Disorders, John Wiley \& Sons, Zurich, Switzerland, 2nd edition, 2002.

[6] Encyclopedia Britannica.

[7] G. Karsenty, "The complexities of skeletal biology," Nature, vol. 423, no. 6937, pp. 316-318, 2003.

[8] B. R. Olsen, A. M. Reginato, and W. Wang, "Bone development," Annual Review of Cell and Developmental Biology, vol. 16, pp. 191-220, 2000.

[9] E. Zelzer and B. R. Olsen, "Multiple roles of vascular endothelial growth factor (VEGF) in skeletal development, growth, and repair," Current Topics in Developmental Biology, vol. 65, pp. 169-187, 2004.

[10] H. M. Kronenberg, "Developmental regulation of the growth plate," Nature, vol. 423, no. 6937, pp. 332-336, 2003.

[11] F. Forriol and F. Shapiro, "Bone development: interaction of molecular components and biophysical forces," Clinical Orthopaedics and Related Research, no. 432, pp. 14-33, 2005.

[12] A. Guadalupe-Grau, T. Fuentes, B. Guerra, and J. A. L. Calbet, "Exercise and bone mass in adults," Sports Medicine, vol. 39, no. 6, pp. 439-468, 2009.

[13] W. A. Horton, "Skeletal development: insights from targeting the mouse genome," The Lancet, vol. 362, no. 9383, pp. 560$569,2003$.

[14] J. A. Ogden and L. C. Rosenberg, "Defining the growth plate," in Behaviour of the Growth Plate, H. K. Uhthoff and J. J. Wiley, Eds., Raven Press, New York, NY, USA, 1988.

[15] N. Ortega, D. J. Behonick, and Z. Werb, "Matrix remodeling during endochondral ossification," Trends in Cell Biology, vol. 14, no. 2, pp. 86-93, 2004.

[16] S. F. Gilbert, Developmental Biology, Sinauer Associates, Sunderland, Mass, USA, 6th edition, 2000.

[17] F. Rauch, "Bone growth in length and width: the Yin and Yang of bone stability," Journal of Musculoskeletal Neuronal Interactions, vol. 5, no. 3, pp. 194-201, 2005.

[18] P. H. L. de Freitas, T. Kojima, S. Ubaidus, et al., "Histological assessments on the abnormalities of mouse epiphyseal chondrocytes with short term centrifugal loading," Biomedical Research, vol. 28, no. 4, pp. 191-203, 2007.
[19] A. C. Abram, T. S. Keller, and D. M. Spengler, "The effects of simulated weightlessness on bone biomechanical and biochemical properties in the maturing rat," Journal of Biomechanics, vol. 21, no. 9, pp. 755-767, 1988.

[20] T. J. Wronski and E. R. Morey, "Recovery of the rat skeleton from the adverse effects of simulated weightlessness," Metabolic Bone Disease and Related Research, vol. 4, no. 6, pp. 347-352, 1983.

[21] M. M. Shimano and J. B. Volpon, "Biomechanics and structural adaptations of the rat femur after hindlimb suspension and treadmill running," Brazilian Journal of Medical and Biological Research, vol. 42, no. 4, pp. 330-338, 2009.

[22] S. R. McGlashan, C. G. Jensen, and C. A. Poole, "Localization of extracellular matrix receptors on the chondrocyte primary cilium," Journal of Histochemistry \& Cytochemistry, vol. 54, no. 9, pp. 1005-1014, 2006.

[23] J. F. Whitfield, "The solitary (primary) cilium-A mechanosensory toggle switch in bone and cartilage cells," Cellular Signalling, vol. 20, no. 6, pp. 1019-1024, 2008.

[24] N. F. Berbari, A. K. O'Connor, C. J. Haycraft, and B. K. Yoder, "The primary cilium as a complex signaling center," Current Biology, vol. 19, no. 13, pp. R526-R535, 2009.

[25] W. A. Beresford, Lecture Notes on Histology, Blackwell Scientific, Oxford, UK, 3rd edition, 1983.

[26] C. A. Poole, A. Matsuoka, and J. R. Schofield, "Chondrons from articular cartilage: III. Morphologic changes in the cellular microenvironment of chondrons isolated from osteoarthritic cartilage," Arthritis and Rheumatism, vol. 34, no. 1, pp. 22-35, 1991.

[27] C. A. Poole, "Articular cartilage chondrons: form, function and failure," Journal of Anatomy, vol. 191, no. 1, pp. 1-13, 1997.

[28] L. Stryer, Biochemistry, W.H. Freeman, New York, NY, USA, 4th edition, 2000.

[29] F. Guilak, A. Ratcliffe, and V. C. Mow, "Chondrocyte deformation and local tissue strain in articular cartilage: a confocal microscopy study," Journal of Orthopaedic Research, vol. 13, no. 3, pp. 410-421, 1995.

[30] K. L. Bennell, M. A. Hunt, T. V. Wrigley, B.-W. Lim, and R. S. Hinman, "Role of muscle in the genesis and management of knee osteoarthritis," Rheumatic Disease Clinics of North America, vol. 34, no. 3, pp. 731-754, 2008.

[31] K. D. Brandt, "Putting some muscle into osteoarthritis," Annals of Internal Medicine, vol. 127, no. 2, pp. 154-156, 1997.

[32] M. Benjamin, H. Toumi, J. R. Ralphs, G. Bydder, T. M. Best, and S. Milz, "Where tendons and ligaments meet bone: attachment sites ('entheses') in relation to exercise and/or mechanical load," Journal of Anatomy, vol. 208, no. 4, pp. 471490, 2006.

[33] G. Riley, "Tendinopathy-from basic science to treatment," Nature Clinical Practice Rheumatology, vol. 4, no. 2, pp. 82-89, 2008.

[34] M. Benjamin and J. R. Ralphs, "Tendons in health and disease," Manual Therapy, vol. 1, no. 4, pp. 186-191, 1996.

[35] M. Benjamin and E. J. Evans, "Fibrocartilage," Journal of Anatomy, vol. 171, pp. 1-15, 1990.

[36] S. L.-Y. Woo, J. A. Weiss, and D. A. M. Da, "Biomechanics and morphology of the medial collateral and anterior cruciate ligaments," in Biomechanics of Diarthrodial Joints, V. C. Mow and S. L.-Y. Woo, Eds., Springer, New York, NY, USA, 1990.

[37] O. S. Mian, J. M. Thom, L. P. Ardigò, A. E. Minetti, and M. V. Narici, "Gastrocnemius muscle-tendon behaviour during walking in young and older adults," Acta Physiologica, vol. 189, no. 1, pp. 57-65, 2007. 
[38] M. Kjær, "Role of extracellular matrix in adaptation of tendon and skeletal muscle to mechanical loading," Physiological Reviews, vol. 84, no. 2, pp. 649-698, 2004.

[39] J. Savolainen, K. Vaananen, J. Puranen, T. E. S. Takala, J. Komulainen, and V. Vihko, "Collagen synthesis and proteolytic activities in rat skeletal muscles: effect of castimmobilization in the lengthened and shortened positions," Archives of Physical Medicine and Rehabilitation, vol. 69, no. 11, pp. 964-969, 1988.

[40] A. Arampatzis, K. Karamanidis, and K. Albracht, "Adaptational responses of the human Achilles tendon by modulation of the applied cyclic strain magnitude," The Journal of Experimental Biology, vol. 210, no. 15, pp. 2743-2753, 2007.

[41] M. V. Narici, C. N. Maganaris, and N. D. Reeves, "Myotendinous alterations and effects of resistive loading in old age," Scandinavian Journal of Medicine and Science in Sports, vol. 15, no. 6, pp. 392-401, 2005.

[42] J. G. Tidball and T. L. Daniel, "Myotendinous junctions of tonic muscle cells: structure and loading," Cell and Tissue Research, vol. 245, no. 2, pp. 315-322, 1986.

[43] E. Passerieux, R. Rossignol, T. Letellier, and J. P. Delage, "Physical continuity of the perimysium from myofibers to tendons: involvement in lateral force transmission in skeletal muscle," Journal of Structural Biology, vol. 159, no. 1, pp. 1928, 2007.

[44] P. A. Huijing, "Muscle as a collagen fiber reinforced composite: a review of force transmission in muscle and whole limb," Journal of Biomechanics, vol. 32, no. 4, pp. 329-345, 1999.

[45] J. V. Pardo, J. D’Angelo Siliciano, and S. W. Craig, "A vinculincontaining cortical lattice in skeletal muscle: transverse lattice elements ("costameres") mark sites of attachment between myofibrils and sarcolemma," Proceedings of the National Academy of Sciences of the United States of America, vol. 80, no. 4, pp. 1008-1012, 1983.

[46] S. F. Street, "Lateral transmission of tension in frog myofibers: a myofibrillar network and transverse cytoskeletal connections are possible transmitters," Journal of Cellular Physiology, vol. 114, no. 3, pp. 346-364, 1983.

[47] S. R. Garfin, C. M. Tipton, S. J. Mubarak, et al., "Role of fascia in maintenance of muscle tension and pressure," Journal of Applied Physiology Respiratory Environmental and Exercise Physiology, vol. 51, no. 2, pp. 317-320, 1981.

[48] J. G. Tidball, "Force transmission across muscle cell membranes," Journal of Biomechanics, vol. 24, supplement 1, pp. 43-52, 1991.

[49] A. L. Mackey, K. M. Heinemeier, S. O. A. Koskinen, and M. Kjaer, "Dynamic adaptation of tendon and muscle connective tissue to mechanical loading," Connective Tissue Research, vol. 49, no. 3-4, pp. 165-168, 2008.

[50] S. M. Phillips, "Physiologic and molecular bases of muscle hypertrophy and atrophy: impact of resistance exercise on human skeletal muscle (protein and exercise dose effects)," Applied Physiology, Nutrition and Metabolism, vol. 34, no. 3, pp. 403-410, 2009.

[51] D. L. Rimoin, G. A. Francomano, A. Giedion, et al., "International nomenclature and classification of the osteochondrodysplasias (1997) international working group on constitutional diseases of bone," American Journal of Medical Genetics, vol. 79, no. 5, pp. 376-382, 1998.

[52] G. R. Mortier, "The diagnosis of skeletal dysplasias: a multidisciplinary approach," European Journal of Radiology, vol. 40, no. 3, pp. 161-167, 2001.
[53] E. Jakkula, J. Lohiniva, A. Capone, et al., “A recurrent R718W mutation in COMP results in multiple epiphyseal dysplasia with mild myopathy: clinical and pathogenetic overlap with collagen IX mutations," Journal of Medical Genetics, vol. 40, no. 12 , pp. 942-948, 2003.

[54] C. G. Bönnemann, G. F. Cox, F. Shapiro, et al., "A mutation in the alpha 3 chain of type IX collagen causes autosomal dominant multiple epiphyseal dysplasia with mild myopathy," Proceedings of the National Academy of Sciences of the United States of America, vol. 97, no. 3, pp. 1212-1217, 2000.

[55] J. Kennedy, G. C. Jackson, F. S. Barker, et al., "Novel and recurrent mutations in the C-terminal domain of COMP cluster in two distinct regions and result in a spectrum of phenotypes within the pseudoachondroplasia-multiple epiphyseal dysplasia disease group," Human Mutation, vol. 25, no. 6, pp. 593-594, 2005.

[56] J. Spranger, "Pattern recognition in bone dysplasias," Progress in Clinical and Biological Research, vol. 200, pp. 315-342, 1985.

[57] A. Mabuchi, N. Manabe, N. Haga, et al., "Novel types of COMP mutations and genotype-phenotype association in pseudoachondroplasia and multiple epiphyseal dysplasia," Human Genetics, vol. 112, no. 1, pp. 84-90, 2003.

[58] J. McKeand, J. Rotta, and J. T. Hecht, "Natural history study of pseudoachondroplasia," American Journal of Medical Genetics, vol. 63, no. 2, pp. 406-410, 1996.

[59] M. D. Briggs, S. M. G. Huffman, L. M. King, et al., "Pseudoachondroplasia and multiple epiphyseal dysplasia due to mutations in the cartilage oligomeric matrix protein gene," Nature Genetics, vol. 10, no. 3, pp. 330-336, 1995.

[60] K. L. Chapman, M. D. Briggs, and G. R. Mortier, "Review: clinical variability and genetic heterogeneity in multiple epiphyseal dysplasia," Pediatric Pathology and Molecular Medicine, vol. 22, no. 1, pp. 53-75, 2003.

[61] K. Halász, A. Kassner, M. Mörgelin, and D. Heinegård, "COMP acts as a catalyst in collagen fibrillogenesis," Journal of Biological Chemistry, vol. 282, no. 43, pp. 31166-31173, 2007.

[62] P. E. Di Cesare, F. S. Chen, M. Moergelin, et al., "Matrixmatrix interaction of cartilage oligomeric matrix protein and fibronectin," Matrix Biology, vol. 21, no. 5, pp. 461-470, 2002.

[63] H. H. Mann, S. Özbek, J. Engel, M. Paulsson, and R. Wagener, "Interactions between the cartilage oligomeric matrix protein and matrilins: implications for matrix assembly and the pathogenesis of chondrodysplasias," Journal of Biological Chemistry, vol. 279, no. 24, pp. 25294-25298, 2004.

[64] P. Holden, R. S. Meadows, K. L. Chapman, M. E. Grant, K. E. Kadler, and M. D. Briggs, "Cartilage oligomeric matrix protein interacts with type IX collagen, and disruptions to these interactions identify a pathogenetic mechanism in a bone dysplasia family," Journal of Biological Chemistry, vol. 276, no. 8, pp. 6046-6055, 2001.

[65] M. J. Rock, P. Holden, W. A. Horton, and D. H. Cohn, "Cartilage oligomeric matrix protein promotes cell attachment via two independent mechanisms involving CD47 and $\alpha \mathrm{V} \beta 3$ integrin," Molecular and Cellular Biochemistry, vol. 338, no. 12, pp. 215-224, 2010.

[66] W. Müller-Glauser, B. Humbel, M. Glatt, et al., "On the role of type IX collagen in the extracellular matrix of cartilage: type IX collagen is localized to intersections of collagen fibrils," Journal of Cell Biology, vol. 102, no. 5, pp. 1931-1939, 1986.

[67] M. H. Irwin, S. H. Silvers, and R. Mayne, "Monoclonal antibody against chicken type IX collagen: preparation, characterization, and recognition of the intact form of type IX collagen secreted by chondrocytes," Journal of Cell Biology, vol. 101, no. 3, pp. 814-823, 1985. 
[68] G. C. Jackson, D. Marcus-Soekarman, I. Stolte-Dijkstra, A. Verrips, J. A. Taylor, and M. D. Briggs, "Type IX collagen gene mutations can result in multiple epiphyseal dysplasia that is associated with osteochondritis dissecans and a mild myopathy," American Journal of Medical Genetics, Part A, vol. 152, no. 4, pp. 863-869, 2010.

[69] C. Fang, C. S. Carlson, M. P. Leslie, et al., "Molecular cloning, sequencing, and tissue and developmental expression of mouse cartilage oligomeric matrix protein (COMP)," Journal of Orthopaedic Research, vol. 18, no. 4, pp. 593-603, 2000.

[70] L. Svensson, A. Aszódi, D. Heinegård, et al., "Cartilage oligomeric matrix protein-deficient mice have normal skeletal development," Molecular and Cellular Biology, vol. 22, no. 12, pp. 4366-4371, 2002.

[71] K. A. Piróg, O. Jaka, Y. Katakura, et al., "A mouse model offers novel insights into the myopathy and tendinopathy often associated with pseudoachondroplasia and multiple epiphyseal dysplasia," Human Molecular Genetics, vol. 19, no. 1, pp. 52-64, 2009.

[72] K. Tan, M. Duquette, A. Joachimiak, and J. Lawler, "The crystal structure of the signature domain of cartilage oligomeric matrix protein: implications for collagen, glycosaminoglycan and integrin binding," FASEB Journal, vol. 23, no. 8, pp. 2490 2501, 2009.

[73] C. B. Carlson, D. A. Bernstein, D. S. Annis, et al., "Structure of the calcium-rich signature domain of human thrombospondin-2," Nature Structural and Molecular Biology, vol. 12, no. 10, pp. 910-914, 2005.

[74] F. Deák, R. Wagener, I. Kiss, and M. Paulsson, "The matrilins: a novel family of oligomeric extracellular matrix proteins," Matrix Biology, vol. 18, no. 1, pp. 55-64, 1999.

[75] O. Schwartz and R. S. Jampel, "Congenital blepharophimosis associated with a unique generalized myopathy," Archives of Ophthalmology, vol. 68, pp. 52-57, 1962.

[76] S. Nicole, C.-S. Davoine, H. Topaloglu, et al., "Perlecan, the major proteoglycan of basement membranes, is altered in patients with Schwartz-Jampel syndrome (chondrodystrophic myotonia)," Nature Genetics, vol. 26, no. 4, pp. 480-483, 2000.

[77] R. V. Iozzo, J. Pillarisetti, B. Sharma, et al., "Structural and functional characterization of the human perlecan gene promoter: transcriptional activation by transforming growth factor- $\beta$ via a nuclear factor 1-binding element," Journal of Biological Chemistry, vol. 272, no. 8, pp. 5219-5228, 1997.

[78] A. C. van Huffelen, F. J. M. Gabreels, J. S. van Luypen van der Horst, et al., "Chondrodystrophic myotonia. A report of two unrelated Dutch patients," Neuropadiatrie, vol. 5, no. 1, pp. 71-90, 1974.

[79] P. R. Huttenlocher, J. Landwirth, V. Hanson, B. B. Gallagher, and K. Bensch, "Osteo-chondro-muscular dystrophy. A disorder manifested by multiple skeletal deformities, myotonia, and dystrophic changes in muscle," Pediatrics, vol. 44, no. 6 , pp. 945-958, 1969.

[80] L. Y. Sakai, D. R. Keene, and E. Engvall, "Fibrillin, a new 350$\mathrm{kD}$ glycoprotein, is a component of extracellular microfibrils," Journal of Cell Biology, vol. 103, no. 6, pp. 2499-2509, 1986.

[81] J. R. Gray and S. J. Davies, "Marfan syndrom," Journal of Medical Genetics, vol. 33, no. 5, pp. 403-408, 1996.

[82] W. M. H. Behan, C. Longman, R. K. H. Petty, et al., "Muscle fibrillin deficiency in Marfan's syndrome myopathy," Journal of Neurology Neurosurgery and Psychiatry, vol. 74, no. 5, pp. 633-638, 2003.
[83] N. C. Voermans, C. G. Bönnemann, P. A. Huijing, et al., "Clinical and molecular overlap between myopathies and inherited connective tissue diseases," Neuromuscular Disorders, vol. 18, no. 11, pp. 843-856, 2008.

[84] J. P. Habashi, D. P. Judge, T. M. Holm, et al., "Losartan, an AT1 antagonist, prevents aortic aneurysm in a mouse model of Marfan syndrome," Science, vol. 312, no. 5770, pp. 117-121, 2006.

[85] A. Campos-Xavier, J. M. Saraiva, R. Savarirayan, et al., "Phenotypic variability at the TGF- $\beta 1$ locus in CamuratiEngelmann disease," Human Genetics, vol. 109, no. 6, pp. 653658, 2001.

[86] M. Ghadami, Y. Makita, K. Yoshida, et al., "Genetic mapping of the Camurati-Engelmann disease locus to chromosome 19q13.1-q13.3," American Journal of Human Genetics, vol. 66, no. 1, pp. 143-147, 2000.

[87] M. E. Dickinson, M. S. Kobrin, C. M. Silan, et al., "Chromosomal localization of seven members of th murine TGF$\beta$ superfamily suggests close linkage to several morphogenetic mutant loci," Genomics, vol. 6, no. 3, pp. 505-520, 1990.

[88] J. Bondestam, H. Pihko, S.-L. Vanhanen, et al., "Skeletal dysplasia presenting as a neuromuscular disorder-report of three children," Neuromuscular Disorders, vol. 17, no. 3, pp. 231-234, 2007.

[89] H. Yoshioka, M. Mino, N. Kiyosawa, et al., "Muscular changes in Engelmann's disease," Archives of Disease in Childhood, vol. 55, no. 9, pp. 716-719, 1980.

[90] T. Inaoka, N. Shuke, J. Sato, et al., "Scintigraphic evaluation of pamidronate and corticosteroid therapy in a patient with progressive diaphyseal dysplasia (Camurati-Engelmann disease)," Clinical Nuclear Medicine, vol. 26, no. 8, pp. 680682, 2001. 

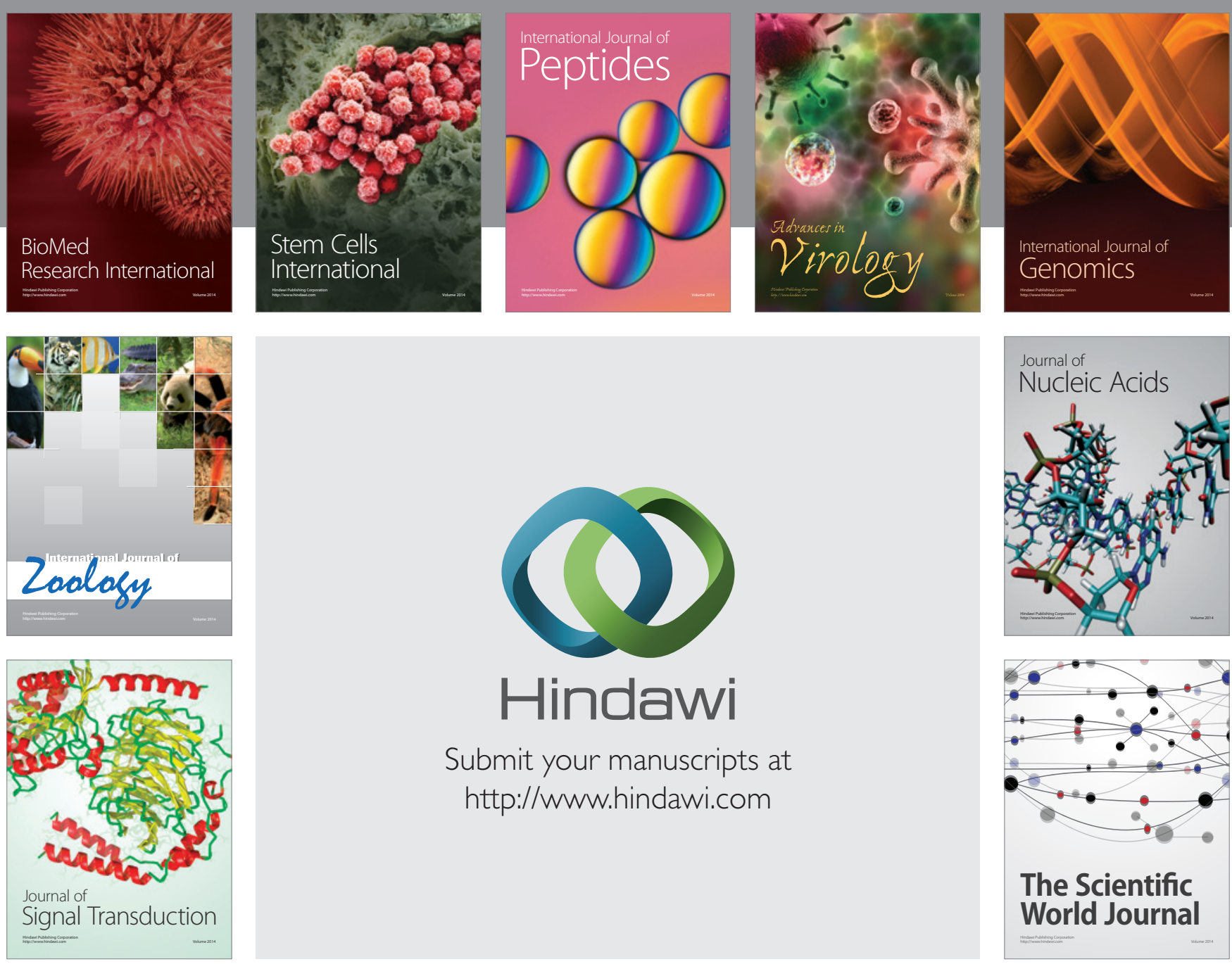

Submit your manuscripts at

http://www.hindawi.com
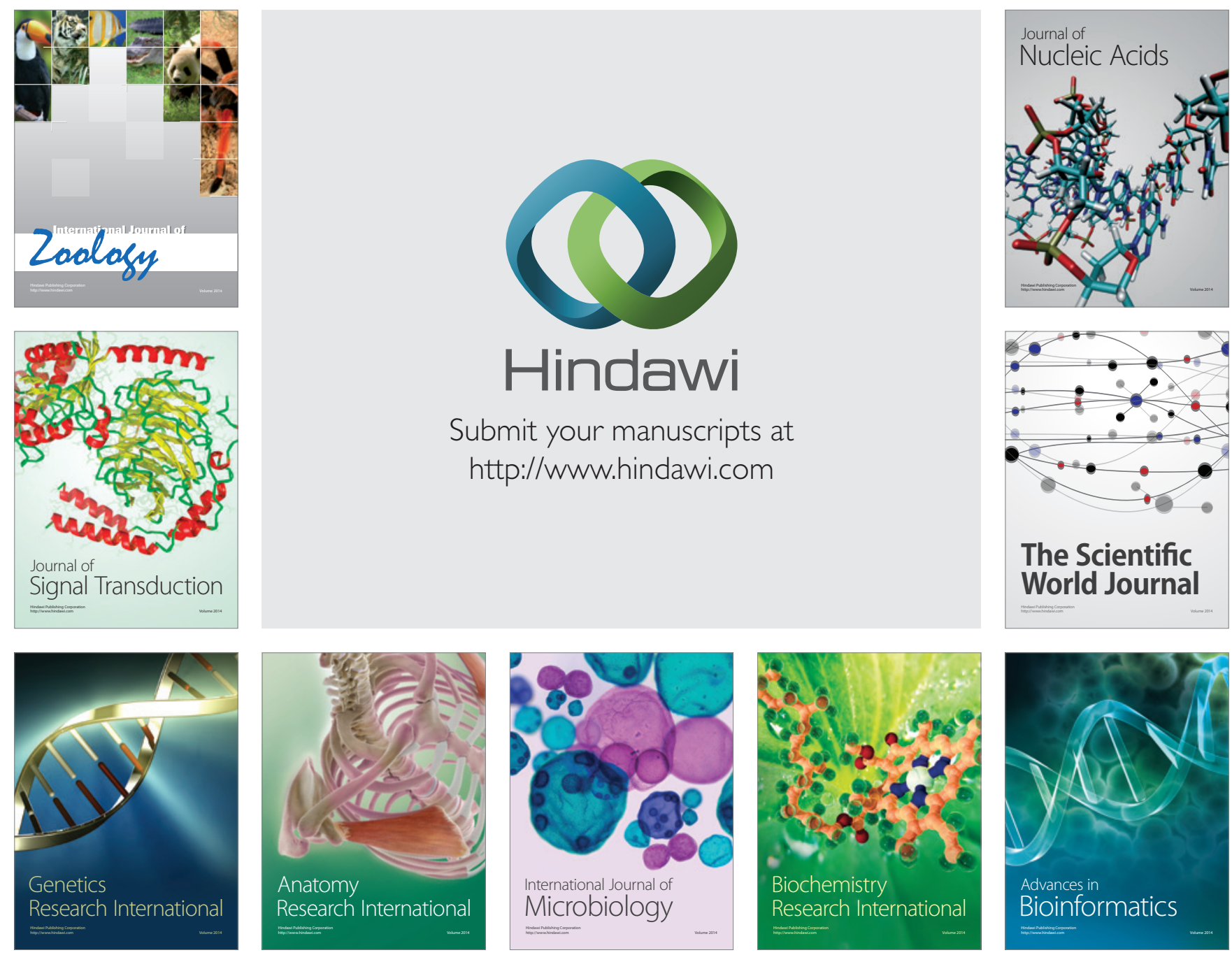

The Scientific World Journal
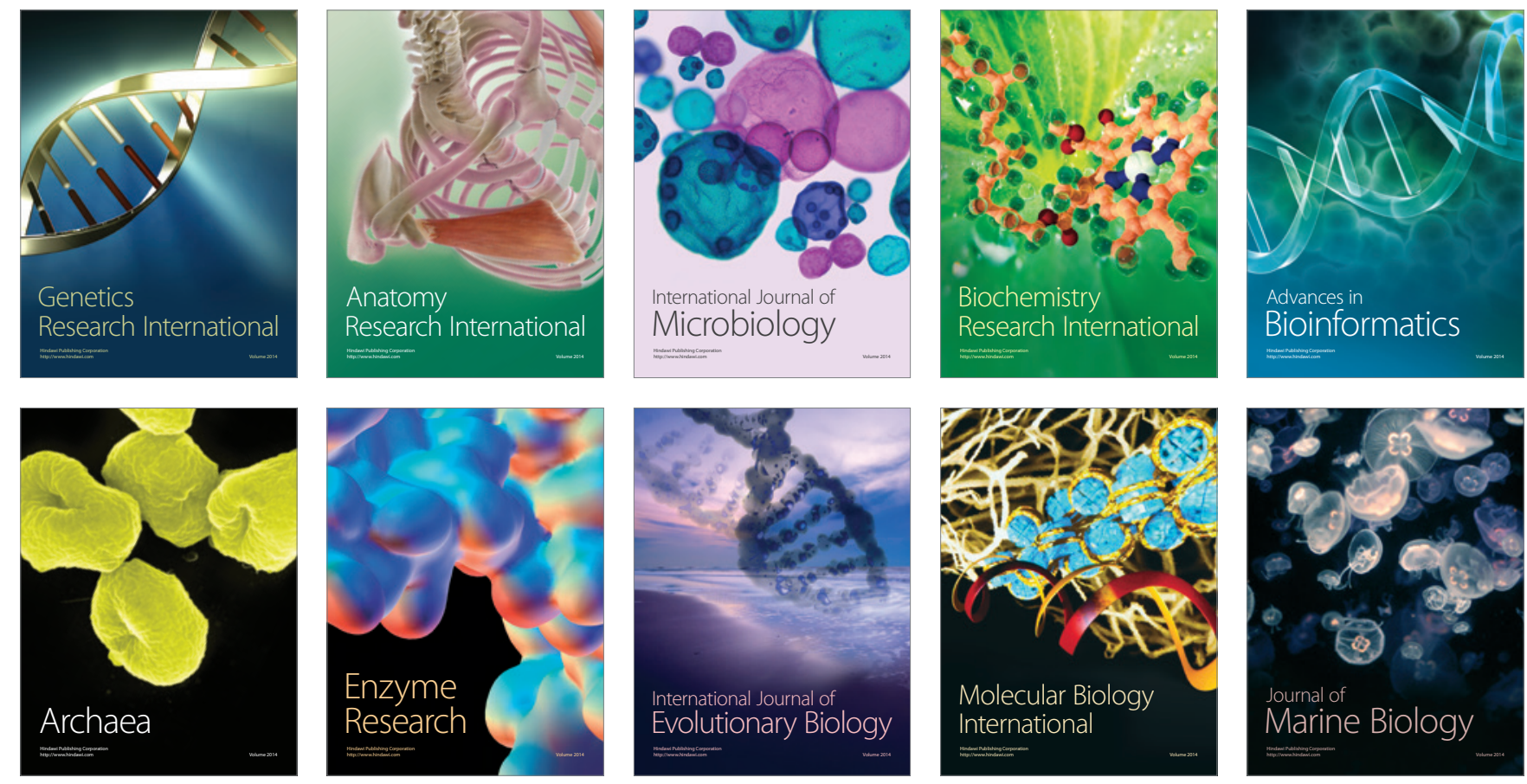